\title{
Research on Sustainable Development Strategies of The agriculture of Hebei Province
}

\author{
Yanna Zhao $^{1}$,YuQiang Sun ${ }^{2}$ \\ 1. Shijiazhuang University of Economics, Shijiazhuang, China \\ 2. Hebei Province Soils and Fertilizers General Station ,Shijiazhuang, China \\ zhyn1023@yahoo.com.cn
}

\section{Keyword:Hebei Province;Sustainable Development;Strategy}

\begin{abstract}
This paper introduces the Changes in agricultural production of Hebei Province from 1949 to 2011,firstly.Then We analyzed the factors that influence the sustainable development of Agriculture.Finally, we put forward some development proposals. We hope to have reference to the other provinces of the sustainable development of agriculture .
\end{abstract}

\section{Analysis on Agricultural Production Status}

The grain production level was rather low before, and only $53.13 \mathrm{~kg}$ of grains were produced per acre in the whole province at the age of 1949. And then with the increasing development of marketing economy, the grain production level has been enhanced also. During the period of 1995 to 2011, the average production throughout the whole province has increased from $267.10 \mathrm{~kg}$ to $336.47 \mathrm{~kg}$, and the overall production has reached to 2.739 million tons and 3.1726 million tons.

\begin{tabular}{|c|c|c|c|}
\hline Year & $\begin{array}{c}\text { Sowing Area } \\
\text { (10 Thousand Acre) }\end{array}$ & $\begin{array}{l}\text { Overall Production } \\
\text { (100 Million Kg) }\end{array}$ & $\begin{array}{l}\text { Yield per Acre } \\
\text { (Kg/Acre })\end{array}$ \\
\hline 1949 & 10864.35 & 46.95 & 43.20 \\
\hline 1995 & 10244.25 & 273.9 & 267.40 \\
\hline 1996 & 10705.95 & 278.95 & 260.53 \\
\hline 1997 & 10649.1 & 274.67 & 257.93 \\
\hline 1998 & 10958.55 & 291.75 & 266.20 \\
\hline 1999 & 10854.15 & 274.63 & 253.00 \\
\hline 2000 & 10378.05 & 255.11 & 245.80 \\
\hline 2001 & 9943.35 & 249.18 & 250.60 \\
\hline 2002 & 9726.6 & 243.58 & 250.40 \\
\hline 2003 & 8766 & 238.78 & 267.80 \\
\hline 2004 & 9005.1 & 248.01 & 275.40 \\
\hline 2005 & 9360.3 & 259.86 & 277.60 \\
\hline 2006 & 9407.55 & 278.06 & 295.60 \\
\hline 2007 & 9252.3 & 284.16 & 307.13 \\
\hline 2008 & 9237.15 & 290.58 & 314.60 \\
\hline 2009 & 9324.75 & 291.02 & 312.07 \\
\hline 2010 & 9423.3 & 297.59 & 315.80 \\
\hline 2011 & 9429.15 & 317.26 & 336.47 \\
\hline
\end{tabular}

In accordance with the social requirement variation, the grain quantity should also be some enhanced. In 1949, sowing area of wheat was 23.657 million acres throughout the province, with $36.5 \mathrm{~kg}$ produced per acre, 0.864 billion $\mathrm{kg}$ in total. And in 2011, sowing area of wheat was 35.9415 million acres, with yield per acre enhanced by 9.7 times and overall yield by 14.8 times.

Chart 2 Sowing Area, Overall Yield and Yield per Acre of Wheat in Hebei Province

$\begin{array}{cccc}\text { Year } & \begin{array}{c}\text { Sowing Area } \\ (10 \text { Thousand Acre })\end{array} & \begin{array}{c}\text { Overall Production } \\ (100 \text { Million Kg })\end{array} & \begin{array}{c}\text { Yield per Acre } \\ \text { (Kg/Acre) }\end{array} \\ 1949 & 2365.65 & 8.64 & 36.53\end{array}$




$\begin{array}{llll}1995 & 3750.90 & 106.03 & 282.67 \\ 1996 & 3886.80 & 113.91 & 293.07 \\ 1997 & 4081.05 & 133.07 & 326.07 \\ 1998 & 4146.00 & 125.36 & 302.40 \\ 1999 & 4094.85 & 128.05 & 312.73 \\ 2000 & 4018.20 & 120.80 & 300.60 \\ 2001 & 3869.70 & 112.27 & 290.13 \\ 2002 & 3674.40 & 109.95 & 299.27 \\ 2003 & 3289.35 & 101.88 & 309.73 \\ 2004 & 3242.25 & 105.32 & 324.87 \\ 2005 & 3565.65 & 115.03 & 322.60 \\ 2006 & 3756.75 & 118.97 & 316.67 \\ 2007 & 3618.60 & 119.37 & 329.87\end{array}$

In 2011, sowing area of rice was 1.245 million acres (increased by 2.2 times than that of 1949), throughout the province, with $483.27 \mathrm{~kg}$ produced per acre (increased by 1.9 times than that of 1949), 0.602 billion $\mathrm{kg}$ in total (increased by 19.4 times than that of 1949).

In 2011, sowing area of corn was 45.537 million acres (2.44 times than that of 1949), throughout the province, with $360.07 \mathrm{~kg}$ produced per acre (7.82 times than that of 1949), 16.394 billion $\mathrm{kg}$ in total (19.04 times than that of 1949).

The development of grain yield drives our life improvement. In 2011, the total population in our province has reached 72.4 million, and the per capita grain quantity has reached $438.2 \mathrm{~kg}$, which was 2.9 times of that in 1949. Among that, the total per capita quantity of both wheat and rice has reached $184.57 \mathrm{~kg}$, enhanced by more than 6 times than that of $19499(29 \mathrm{~kg})$.

\section{Problems Exited in Agricultural Sustainable Development}

\section{Low Yield}

It is calculated that the total sowing area of grain at the age of 2010 was 94.233 million acres (5.72\% of that of whole country), ranking the $6^{\text {th }}$; yield per acre (rice, wheat and corn) was $325 \mathrm{~kg}$, $43 \mathrm{~kg}$ less than the national level of $368 \mathrm{~kg}$ ); the total yield was 29.759 million tons (5.45\% of the national level), ranking the $7^{\text {th }}$.

\section{Unstable Yield}

During the period of 1985 to 2011, there were 10 years (37\%) when the total grain yield was lower than that of the last year, among which 3 years with ever decreasing yield (1986-1987, 1991-1992 and 1999-2003). Especially speaking, in 2003, it decreased 3.59 million tons than that of 1997.

\section{Unstable Production}

Due to differences in nature, economy and technology, the grain production capability is very unstable. In 2011, there were 27 counties with $300 \mathrm{~kg}$ (19.3\% of that of Hebei Province), 44 counties with 300-400 kg (31.5\% of that of Hebei Province), 69 counties with over $400 \mathrm{~kg}$ (49.2\% of that of Hebei Province). What's worse, differences between different terrains were also large then.

\section{Quality of Grain cannot Fit the Social Development and our Life}

In Hebei Province, sowing area of high-quality wheat was only $41 \%$, 55\% lower than the national average level. High-quality wheat mainly refers to hard ones with high nutritional quality and processing quality, owning full seeds and high flour yield.

\section{Factor Analysis on Barrier in Agricultural Sustainable Development}

\section{Farmers Have Little Enthusiasm to Grow}

With the development of comedy production, there are throughout the province totally $20 \%-30 \%$ of famers work out, especially in developed suburbs, for increasing of prices of the materials for 
agricultural production has drove the production costs. It is reported that the agricultural cost for each acre has increased by more than 12 times, say, from 22.19 yuan in 1978 to 285.8 yuan in 2010; income gap between agriculture and industry has expanded too; furthermore, because the unreasonable price ration agriculture and industry, low socialization service level and so on all drive week production increase potential, unsatisfying benefit and farmers’ decreasing enthusiasm.

\section{Frequent Natural Disasters}

From 1995 to 2006, there were at average 27.71 million acres of lands encountered natural disasters per year (7.95 million acres in 2006). During the period of 207 to 2011, we speeded the construction of farmland water conservancy works, which better the irrigation capability and deduced the percentage of the disaster areas (7.2 million acres in 2011 with 0.9 million acres decreased for natural disasters). Besides, the water resource is rather short. It is calculated that the usable water resource in Hebei Province in 2011 was only 15.72 billion $\mathrm{m}^{3}$, but we usually need 27.3 billion $\mathrm{m}^{3}$ of water each year.

\section{Sowing Areas of Grains Decrease}

From 1949 to 2011, sowing areas in the whole province decreased from 108.64 million acres to 94.29 million acres (decreased by 13.2\%) and the per capita sowing area decreased from 3.52 acres to 1.30 acres etc.

\section{Analysis on Agricultural Sustainable Development Strategy in Hebei Province}

Though we are faced with series of problems, the basic strategy to solve agricultural sustainable development is to improve the production capability and enhance the supplying stability.

\section{Perfect Agroecological Environment and Develop Agricultural Resources Unreasonably}

We should always pay our attention to protect farmland, solve the problem of water shortage, develop dry farming and enhance water utilization rate. We should in details enhance infrastructure construction and improve production situations. At first, we should protect farmlands, making sure of enough sowing area, to develop efficient agriculture and keep the stability of grains production and supply \& demand balance. Secondly, we should improve production capability by bettering low and middle yield lands. Then, we should highly develop agricultural ecological chain and ecological agriculture, to achieve the virtuous circle in agricultural ecological system. At last, we should protect the environment by retain forests, lakes and grasses in lands unfit tillage.

\section{Conduct Comprehensive Development to Achieve diversification of Grain Variety}

When our requirements and needs towards food change, it is necessary to increase the supply making use of various resources, or it will results in gap in supply \& demand. At the same time, we should also expand the food sources in accordance with our facts, to correctly lead citizens' food consumption.

\section{Reasonably Lead Grain with Feed Production}

There currently exist lots of problems in grains with feeds: Firstly, the production of feeds depends on that of grains. Secondly, the feed structure was simplex without enough protein feed, thus leading decreasing animal husbandry production efficiency. Hence, we should plant enough feeds, establishing new agricultural sowing system by transferring the binary system with grain-economic crops to ternary system with grain-economic crops-feed.

\section{Make Fullest of International Agricultural Products Market}

It is necessary for us to import some grain varieties with high quality and low price, aiming at addressing the unbalance between variety shortage, non-harvest and regional demand. In addition, we should improve the grain production quality and develop high-quality grains to fit the new national situation after being a member nation of WTO.

\section{Accelerate Agricultural Technical Improvement and Enhance Technological Contribution}

Grain Safety should cover meaning in 2 aspects, i.e. quantity and quality. At first, we should make efforts to enhance agricultural strength with technology by actively arranging research institute and technical staff to perfect agricultural technologies, selecting products with high quality, yield and high efficiency, and building better breeding bases. Furthermore, we should promote new technologies and new achievements. We should predominately develop \& use resources, updating 
varieties and make use of relevant technologies, to promote technological achievement \& advanced technologies and facilitate the transformation from the traditional agriculture to the modern one. Finally, it is significant for us to further establish and complete rural science \& technology network and enhance and promote technological administration and service on the whole.

\section{Reference}

[1]LIU Chang-Jiang.Strategic thought for sustainable agriculture development and industrialization in Northeast China.Chinese Journal of Eco-Agriculture.vol 1(2011)

[2]Tian Wan-hui.Analysis on the Main Barriers of Sustainable Development of Agriculture in Lanzhou—And Discussion to the Multi-functionality of Agriculture.Journal of Lanzhou Commercial College,vol 1(2011)

[3]Ouyang Tao; Xiao Haiyan; Yuan Huibin .The Empirical Aanlysis Of Sustainable Development Of Hunan Provinces Agriculture.Chinese Journal of Agricultural Resources and Regional Planning,vol 1(2011)

[4] Yang hui.Problems and Countermeasures of Agricultural Sustainable Development in China. Modern Agricultural Sciences and Technology, vol 1(2011)

[5] Cheng ning.Evaluation of sustainable agricultural development in Fujian. Taiwan Agricultural Research, vol 1(2011) 